\title{
Investigation of T-H-M-C processes on sealing systems in rock salt
}

\author{
THORSTEN MEYER*, KYRA JANTSCHIK, OLIVER \\ CZAIKOWSKI \\ Gesellschaft für Anlagen und Reaktorsicherheit \\ (GRS gGmbH), Theodor-Heuss-Str. 4, \\ 38122 Braunschweig, Germany \\ *correspondence: thorsten.meyer@grs.de
}

In Germany, the disposal of radioactive waste is foreseen in deep geological formations. To ensure that radionuclides are isolated from the biosphere, shafts and drifts from mining activities need to be closed with sealings from adequate construction material. Therefore, a sealing system consists of the sealing material itself, the excavation damaged zone (EDZ) and the contact seam between sealing material / EDZ.

In the context of the national research Project "THyMeCZ" (FKZ: 02 E11698), GRS is currently investigating sealing and backfilling materials for nuclear repositories in salt formations. The program aims at providing process understanding and experimentally based parameters needed for the long-term performance assessment of the sealing system.

The experiments focuse on the long-term sealing behaviour of the system under various conditions, e.g. contact with saline solutions, mechanical stress and increased temperatures. The sealing system is simulated in laboratory experiments using hollow cylinders of rock salt filled with concrete sealing material.

The influence of thermal $(\mathrm{T})$, hydraulic $(\mathrm{H})$, mechanical (M) and chemical (C) impacts to the sealing performance of the lab-scale sealing system is systematically investigated:

- Percolation of the system with saline solutions: investigation of changes in fluid permeability, solution composition and the phase ensemble with time due to material deterioration/corrosion (HC).

- Exposition to various stress states with and without percolation of saline solutions: Determination of fluid permeability as well as changes in solution composition and the resulting phase ensemble (HMC).

- Percolation of the system with brines at elevated temperature: investigation of the influence of temperature on the hydraulic and chemical parameters with time. (THC).

- Exposition to various stress states and percolation with saline solutions at elevated temperatures. A new experimental setup for these investigations is built, based on corrosionresistant syringe pumps (THMC).

This paper will present selected results from laboratory experiments at GRS. 
This abstract is too long to be accepted for publication.

Please revise it so that it fits into the column on one page. 